\title{
Reprogramming of antiviral T cells prevents inactivation and restores $T$ cell activity during persistent viral infection
}

\author{
David G. Brooks, Dorian B. McGavern, and Michael B.A. Oldstone \\ Viral Immunobiology Laboratory, Molecular and Integrative Neuroscience Department, and Department of Infectology, \\ The Scripps Research Institute, La Jolla, California, USA.
}

\begin{abstract}
Failure to clear persistent viral infections results from the early loss of $T$ cell activity. A pertinent question is whether the immune response is programmed to fail or if nonresponsive $T$ cells can specifically be fixed to eliminate infection. Although evidence indicates that $T$ cell expansion is permanently programmed during the initial priming events, the mechanisms that determine the acquisition of $T$ cell function are less clear. Herein we show that in contrast to expansion, the functional programming of $T$ cell effector and memory responses in vivo in mice is not hardwired during priming but is alterable and responsive to continuous instruction from the antigenic environment. As a direct consequence, dysfunctional $T$ cells can be functionally reactivated during persistent infection even after an initial program of inactivation has been instituted. We also show that early therapeutic reductions in viral replication facilitate the preservation of antiviral $\mathrm{CD4}^{+} \mathrm{T}$ cell activity, enabling the long-term control of viral replication. Thus, dysfunctional antiviral $\mathrm{T}$ cells can regain activity, providing a basis for future therapeutic strategies to treat persistent viral infections.
\end{abstract}

\section{Introduction}

It is crucial for the eradication of established persistent viral infections that the host's antiviral immune response be functionally restored. Concomitant with the establishment of viral persistence, antiviral $\mathrm{CD}^{+}$and $\mathrm{CD}^{+} \mathrm{T}$ cells become nonresponsive toward viral antigens and are either physically deleted or persist in an inactivated state (1-4). T cell inactivation is observed during a variety of different persistent viral infections, including HIV, HBV, and HCV in humans and lymphocytic choriomeningitis virus (LCMV) in rodents $(1,2,5-11)$, suggesting a common mechanism influencing $\mathrm{T}$ cell responses. The failure to sustain $\mathrm{T}$ cell activity is directly associated with the inability to clear the infection, as evidenced by the fact that adoptive transfer of responsive virus-specific $T$ cells can completely eliminate an established persistent infection (12). A relationship between $\mathrm{T}$ cell functionality and viral clearance is further supported by the correlation between the strength of the $\mathrm{T}$ cell responses and the clearance of $\mathrm{HCV}$ infection $(7,13)$ and the fact that control of HIV infection is associated with increased $\mathrm{T}$ cell responsiveness (14). Thus, it is important to develop strategies to boost the host's endogenous $\mathrm{T}$ cell responses to control infection.

$\mathrm{T}$ cell inactivation has been recognized during persistent viral infection; however, whether it is programmed during the initial priming events and thus a predestined, irreversible outcome of infection or if instead the nonresponsive $\mathrm{T}$ cells can be reprogrammed and fixed to respond after priming is unknown. In response to an acute antigenic challenge, the initial priming events alone instruct a specific program of expansion, acquisition of effector functions, and memory $T$ cell development (15-21). However, these studies focus on a single antigenic encounter (priming

Nonstandard abbreviations used: Arm, Armstrong; Cl, clone; $\mathrm{GP}_{61-80}$, glycoprotein $_{61-80}$; LCMV, lymphocytic choriomeningitis virus.

Conflict of interest: The authors have declared that no conflict of interest exists. Citation for this article: J. Clin. Invest. 116:1675-1685 (2006). doi:10.1172/JCI26856 followed by removal from the antigenic environment) and do not separate these initial events from the later (post-priming) requirement for/effects of continuous instruction that may be important for $\mathrm{T}$ cell development and function. Moreover, the impact that repetitive antigenic stimulation (as encountered during chronic infections) has on the developmental program initiated during priming is not clear. Importantly, if T cell function, and specifically inactivation, is programmed during priming, then it is unlikely that therapeutic intervention employed past the priming phase of a persistent infection will rescue cell function. However, if virusspecific $T$ cells remain functionally malleable throughout the course of a persistent infection, then they could serve as targets for therapeutic manipulation.

Studies in humans illustrate that therapeutically suppressing viral replication during chronic infection causes a corresponding increase in $\mathrm{T}$ cell activity, particularly when therapy is initiated during the acute phase of infection $(6,10,22-28)$. The ability to revive $\mathrm{T}$ cell responses during persistent viral infections have most thoroughly been analyzed following treatment interruption in HIV-infected patients (29-31), although similar results were observed during treatment of other persistent viral infections. Administration of antiviral therapies during acute HIV infection is associated with increased virus-specific $\mathrm{CD}^{+} \mathrm{T}$ cell responses (in both number and breadth) and a corresponding decrease in viremia $(23,26)$. However, when treatment was interrupted during the chronic phase of infection, virus was no longer well controlled. Moreover, isolation of $\mathrm{CD}^{+} \mathrm{T}$ cells from HIV-infected patients followed by in vitro culture in the presence of IL-2 renewed their proliferative capacity (5) and ability to produce IFN- $\gamma$ (32). Thus, these studies suggested that $\mathrm{T}$ cell activity could be resurrected if viral replication were subdued. However, such studies, performed in human and nonhuman primates, were unable to determinate whether the resurgent $T$ cell activity observed following therapy actually resulted from (a) the reactivation of antigen-experienced, nonresponsive T cells, (b) de novo activation of naive $\mathrm{T}$ cells that 
A

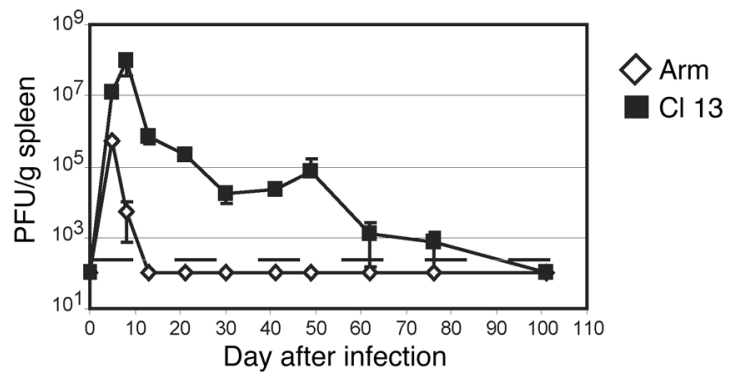

B

Day 5 after infection

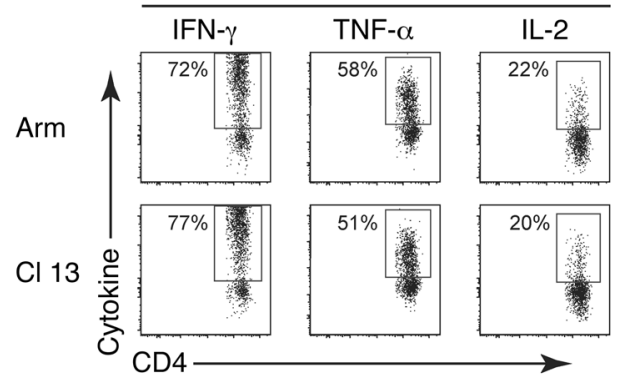

C

Day 5 after infection

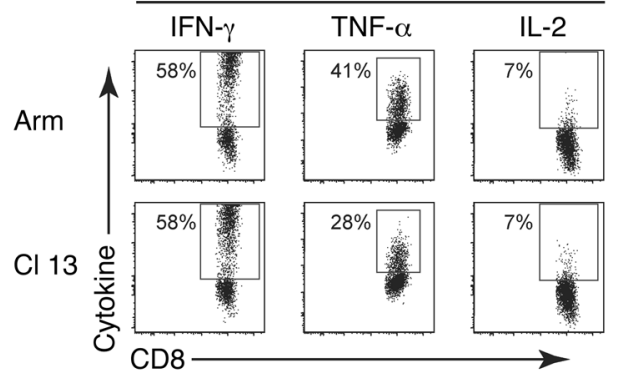

Day 9 after infection

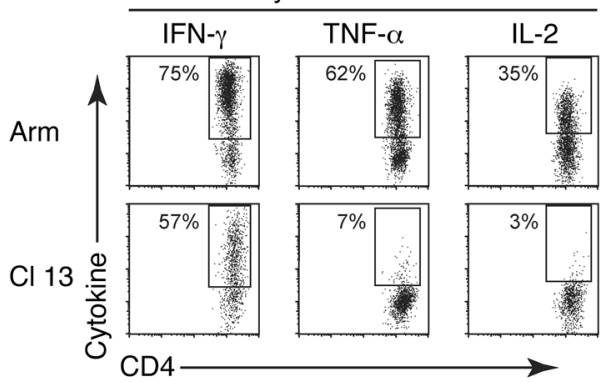

Day 9 after infection

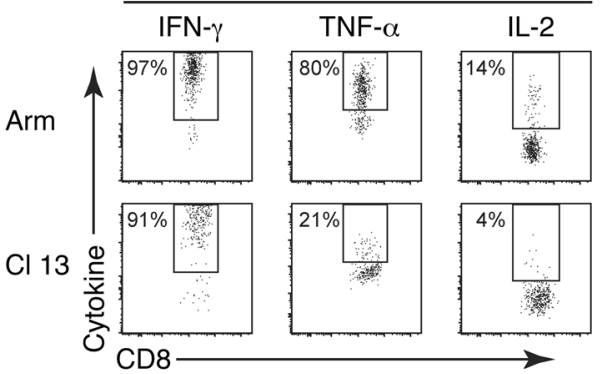

Figure 1

Virus-specific CD4 ${ }^{+}$and $C D 8^{+} T$ cells lose initially strong activity during the establishment of a persistent viral infection. (A) Spleens were isolated from LCMV Arm- (open diamonds) and $\mathrm{Cl}$ 13-infected (filled squares) animals and titers of infectious virus determined by plaque assay. Data are expressed as plaque forming units per gram of spleen. The dashed line indicates the lower limit of detection (200 PFU/g spleen). Each time point represents the average \pm 1 SD of 3 mice per group. (B and C) LCMV-specific SMARTA (TCR Tg CD4+ T cells) (B) and P14 (TCR Tg CD8 ${ }^{+} \mathrm{T}$ cells) cells $(\mathrm{C})$ were cotransferred into mice that were subsequently infected with LCMV Arm or $\mathrm{Cl} 13$. On days 5 (left panels) and 9 (right panels) after infection, splenocytes from individual mice were isolated and the frequency of IFN- $\gamma-$, TNF- $\alpha-$, and IL-2-producing SMARTA and P14 cells assessed by intracellular cytokine staining. The flow plots are gated on SMARTA (B) and P14 (C) cells, and the values represent the percentage of cytokine-producing cells. The flow plots are representative of 4 independent experiments containing 4 mice per group. had not previously encountered antigen, or (c) the outgrowth and redistribution of a few functionally competent cells that thrive in situations of decreased viral replication.

In this study we distinguish between these possibilities and specifically analyze whether the initial priming events specifically direct $\mathrm{T}$ cell nonresponsiveness and whether nonresponsive $\mathrm{CD}^{+}$and $\mathrm{CD}^{+} \mathrm{T}$ cell function can be restored during persistent infection. To address this issue, we employed LCMV infection in its natural rodent host. Here we demonstrate that $\mathrm{T}$ cell function is not programmed during priming but rather is an ongoing and, importantly, alterable process. The priming events during the establishment of a persistent infection are inherently productive and provide the initial instruction for the development of $\mathrm{T}$ cell effector and memory responses. As a result, despite prolonged periods of inactivation, $\mathrm{CD} 4^{+}$and $\mathrm{CD}^{+} \mathrm{T}$ cells retain the ability to recover their activity during persistent infection. Significantly, therapeutic reduction of viral loads early during persistent infection preserves $\mathrm{CD}^{+} \mathrm{T}$ cell function in vivo and, as a consequence, has a long-term effect on the control of viral replication.

\section{Results}

$\mathrm{CD}^{+}$and $\mathrm{CD} 8^{+} \mathrm{T}$ cells mount robust responses early during persistent viral infection. We initially analyzed $\mathrm{CD}^{+}$and $\mathrm{CD}^{+} \mathrm{T}$ cell responses in an acute, self-limited LCMV infection compared with those in a persistent infection. Before initiating infection, Thy $1.1^{+} \mathrm{TCR}$ transgenic CD4 ${ }^{+} \mathrm{T}$ cells (SMARTA cells; specific to the LCMV glycoprotein $_{61-80}\left[\mathrm{LCMV}_{-\mathrm{GP}_{61-80}}\right]$ peptide presented in the context of I-A ${ }^{\mathrm{b}}$ ) and Thy $1.1^{+}$TCR transgenic CD8 ${ }^{+} \mathrm{T}$ cells (P14 cells; specific to LCMV-GP $\mathrm{C}_{33-41}$ peptide presented in the context of $\mathrm{H}-2 \mathrm{D}^{\mathrm{b}}$ ) were cotransferred into Thy $1.2^{+} \mathrm{C} 57 \mathrm{BL} / 6$ mice. These cotransfers enabled simultaneous visualization of LCMV-specific $\mathrm{CD}^{+}$and $\mathrm{CD}^{+} \mathrm{T}$ cell populations and responses separately from endogenous responses and allowed the monitoring of a single population of cells throughout the entire course of infection without contamination from new thymic emigrants. We avoided the problems associated with using large, nonphysiologic numbers of transferred transgenic T cells (33) by cotransferring 1,000 $\mathrm{CD}^{+}$and $\mathrm{CD}^{+} \mathrm{T}$ cells. Importantly, each of these transgenic $\mathrm{T}$ cell populations behaved similarly to their endogenous (i.e., host-derived) $\mathrm{CD}^{+}$and $\mathrm{CD}^{+} \mathrm{T}$ cell counterparts, based on $\mathrm{MHC}$ class I and class II tetramer analysis and intracellular cytokine staining (refs. 1 and 2 and data not shown). Two days after cell transfer, mice were infected with LCMV Armstrong (LCMV Arm) or LCMV clone (LCMV Cl) 13.

The LCMV variant $\mathrm{Cl} 13$ evolved during a natural infection with Arm (34) and induces immunosuppression due to a single amino acid change in its glycoprotein that enables high-affinity binding to DCs that express $\alpha$-dystroglycan (35-37). LCMV Cl 13 retains $\mathrm{CD}^{+}$and $\mathrm{CD}^{+} \mathrm{T}$ cell epitopes identical to those of LCMV Arm (38) but alters the ability of DCs to activate T cells. As a result, $\mathrm{Cl}$ 13 caused a persistent infection lasting approximately 60-80 days (Figure 1A). In contrast, LCMV Arm-infected minimal numbers 
A

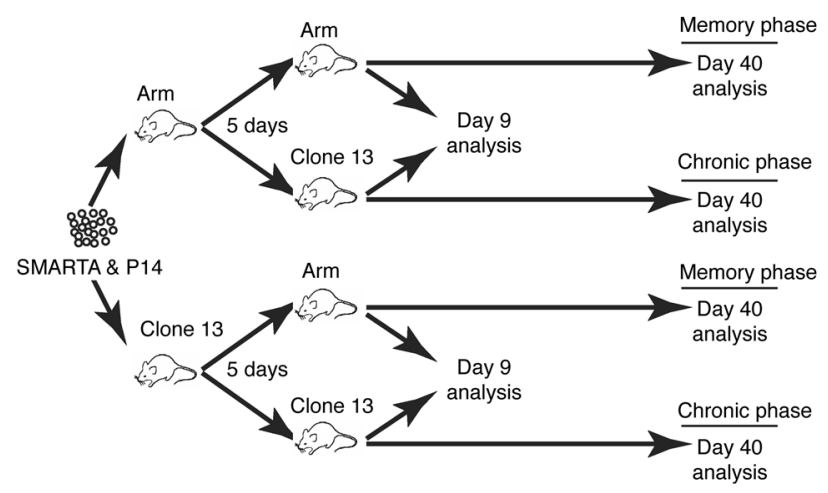

B

Day 9

(day 4 after transfer)
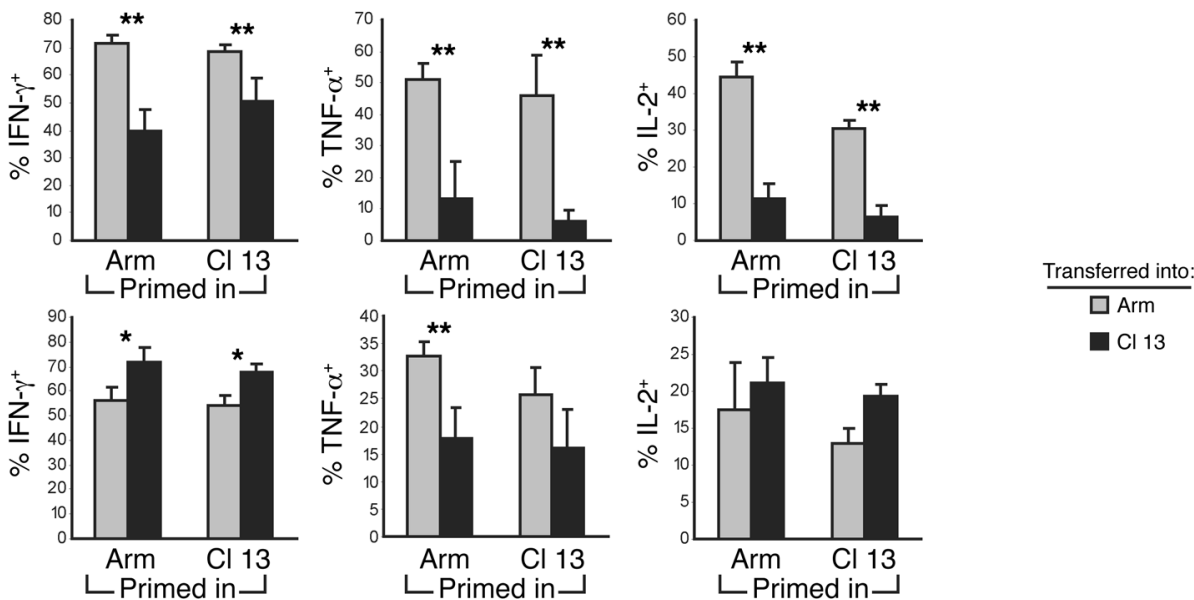

C

Day 40

(day 35 after transfer)

Day 9

(day 4 after transfer)
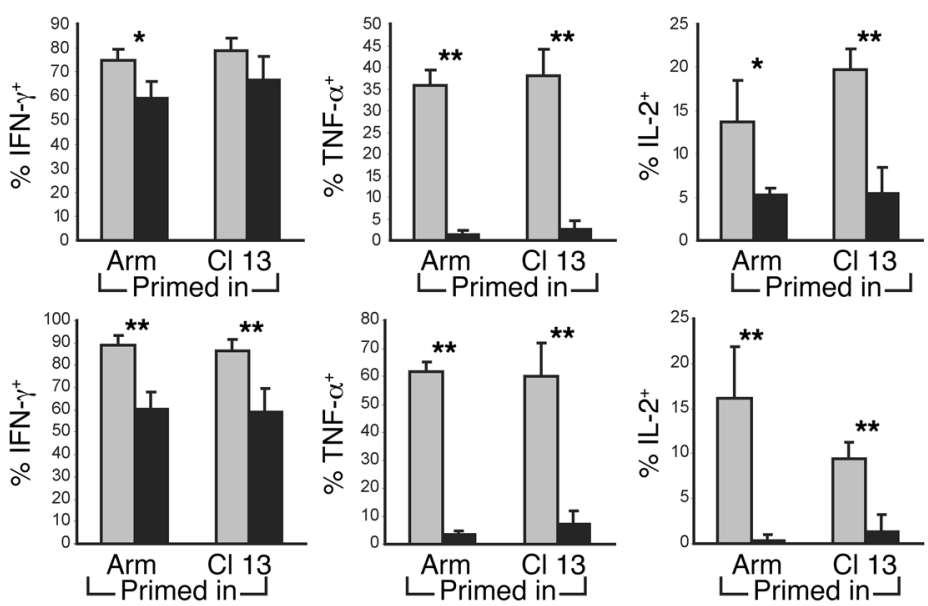

\section{Figure 2}

T cell function is not programmed during priming but is an ongoing process. (A) SMARTA and P14 cells were cotransferred into mice, followed 2 days later by infection with LCMV Arm or Cl 13. Five days after infection, following T cell priming, splenocytes from LCMV Arm- or $\mathrm{Cl}$ 13-infected mice were isolated and pooled separately. B cells were depleted by positive selection, and the remaining "untouched" splenocytes were transferred into recipient mice infected in parallel with LCMV Arm or Cl 13 five days earlier but not given SMARTA and P14 cells. T cells from the recipient mice were analyzed at 9 and 40 days after infection. (B and C) Cotransferred SMARTA and P14 cells were primed in LCMV Arm- or Cl 13-infected animals for 5 days and then transferred into mice infected in parallel with either LCMV Arm or $\mathrm{Cl} 13$ four (top panels) and 35 (bottom panels) days following transfer of the primed cells (days 9 and 40 after infection, respectively). Splenocytes from each mouse were isolated, and the ability of the cotransferred SMARTA (B) and P14 cells (C) to produce IFN- $\gamma$, TNF- $\alpha$, and IL-2 was analyzed by intracellular flow cytometry. The type of infection in which the cells were primed is indicated underneath each graph. Gray and black bars represent transfer into LCMV Arm- and Cl 13-infected recipients, respectively. The bars represent the average \pm SD of 4 mice in each group and are representative of 2-4 experiments. Note that the scales on the $y$ axis differ for the cytokines analyzed. *Statistically significant difference $(P \leq 0.05)$ between cells primed in the same environment and then transferred into LCMV Arm- or Cl 13-infected animals; ${ }^{* *} P \leq 0.01$. 
A

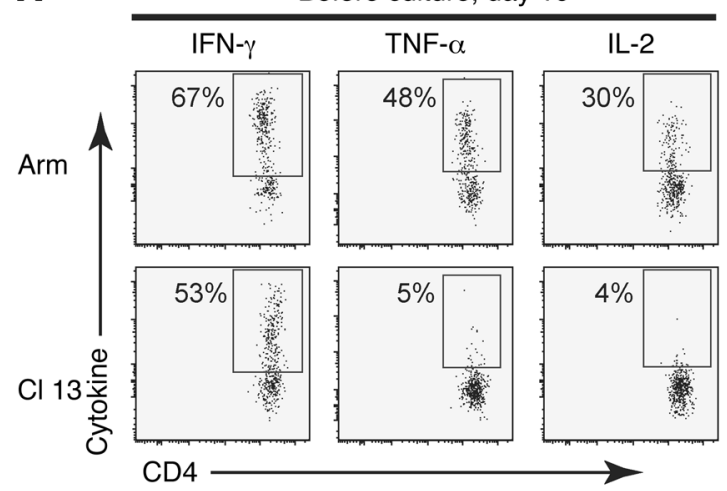

B

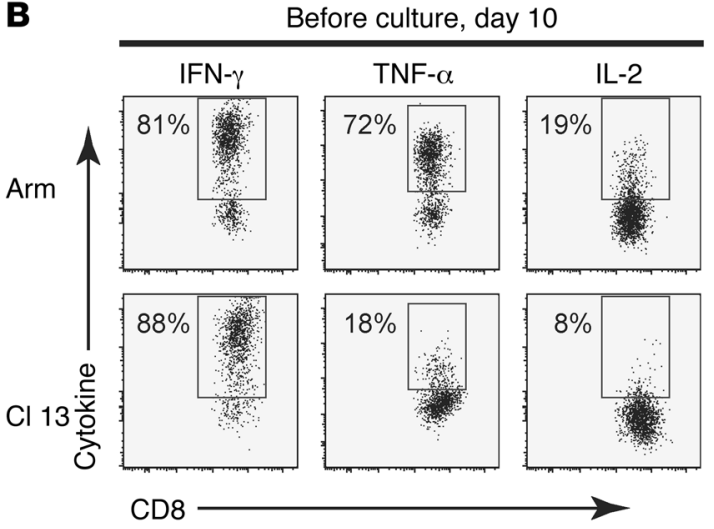

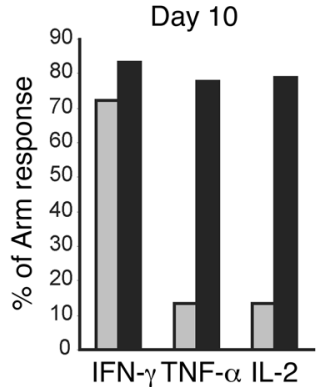

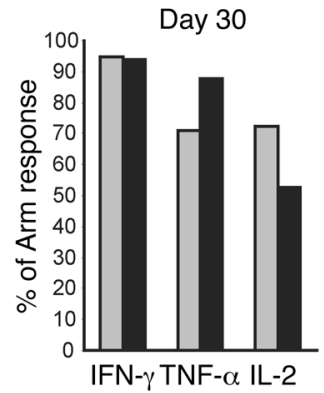

$\square$ Before culture

After culture

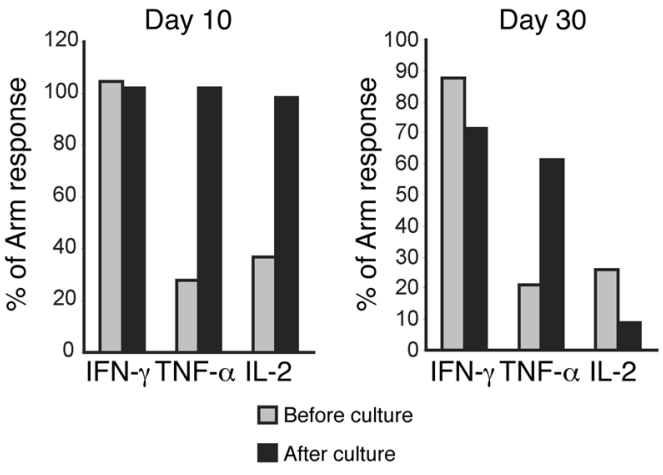

\section{Figure 3}

Reversal of T cell inactivation during persistent viral infection. (A) SMARTA cells from LCMV Arm- (top panels) or Cl 13-infected (bottom panels) mice were isolated 10 days after infection and pooled separately. The numbers in each flow plot indicate the frequency of SMARTA cells on day 10 after LCMV Arm or Cl 13 infection that produced IFN- $\gamma$, TNF- $\alpha$, and IL-2 prior to culture. SMARTA cells isolated on day 10 or 30 after Arm or $\mathrm{Cl} 13$ virus infection were analyzed directly ex vivo or were sorted and cultured for 4 days. The bars in each graph indicate the percentage of IFN- $\gamma-$, TNF- $\alpha-$, and IL-2-producing SMARTA cells prior to the ex vivo culture and following the 4-day culture. The individual bars indicate the frequency of SMARTA cells during LCMV CI 13 infection that produce each cytokine represented as a percentage of SMARTA cells that produced the same cytokine during LCMV Arm infection. Each group contained cells pooled (prior to sorting) from 2-3 spleens, and the data are representative of at least 2 repeat experiments. (B) The ability of P14 cells (isolated from the same animals as represented in $\mathbf{A}$ ) to produce IFN- $\gamma$, TNF- $\alpha$, and IL-2 on day 10 after LCMV Arm or Cl 13 infection is shown in the dot plots, and the graphs illustrate the pre- (gray bars) and post-culture (black bars) levels of cytokine-producing P14 cells from LCMV Cl 13-infected animals represented as a percentage of the P14 response observed during LCMV Arm infection.

of DCs and stimulated the generation of a vigorous anti-LCMV $\mathrm{T}$ cell response that efficiently eliminated viral infection within 7-12 days (Figure 1A). Cotransfer of the SMARTA and P14 cells did not alter the kinetics of viral infection (data not shown). Five days after Arm or $\mathrm{Cl} 13$ exposure, LCMV-specific $\mathrm{CD}^{+}$and $\mathrm{CD}^{+}$ $\mathrm{T}$ cells produced similar cytokine responses (Figure 1, B and C). By day 9, LCMV Arm infection was cleared, and virus-specific CD $4^{+}$ and $\mathrm{CD}^{+} \mathrm{T}$ cells continued to display effector functions (Figure 1, $\mathrm{B}$ and $\mathrm{C}$ ). In contrast, at 9 days after $\mathrm{Cl} 13$ infection, virus-specific $\mathrm{CD}^{+} \mathrm{T}$ cells made less IFN- $\gamma$ and negligible amounts of IL- 2 or TNF- $\alpha$ (Figure 1B). At the same time, virus-specific $\mathrm{CD}^{+} \mathrm{T}$ cells also lost the ability to produce TNF- $\alpha$ and IL-2 (Figure 1C). Thus, in spite of initially strong responses, $\mathrm{T}$ cells rapidly lost function during persistent infection.

Functional T cell programming is altered by persistent viral infection. The progressive loss of T cell activity during persistent infection suggested that functional antiviral responses are not preset. To determine how $T$ cells assumed function during an antiviral immune response, we transferred SMARTA and P14 cells into recipient mice that were subsequently infected with LCMV Arm or Cl 13 (Figure 2A). Five days after infection, following priming and the initial expansion (ref. 2 and data not shown), splenocytes were isolated from Arm- or Cl 13-infected animals. To avoid inclusion of antiviral antibodies, which might influence viral replication kinetics, splenocytes were depleted of B cells before transfer into infected recipients. Cell transfer from Arm- or $\mathrm{Cl} 13$-infected animals did not alter the viral titers or clearance kinetics in the recipient mice (data not shown). Splenocytes from these recipients were then isolated on day 9 and day 40 after infection. SMARTA and P14 cells primed during Arm infection and subsequently transferred into Arm-infected animals efficiently produced IFN- $\gamma$, TNF- $\alpha$, and IL- 2 at 9 days after infection, whereas cells primed in a $\mathrm{Cl} 13$-infected environment and then transferred into $\mathrm{Cl} 13$-infected mice had a significantly decreased ability to produce these cytokines (Figure 2, B and C). These data illustrate that transfer itself did not alter $\mathrm{CD}^{+}$or $\mathrm{CD}^{+} \mathrm{T}$ cell function. However, when SMARTA cells were primed in Arm-infected animals and transferred into $\mathrm{Cl} 13-$ infected recipients, a 4-fold decrease in the frequency of IL-2- 

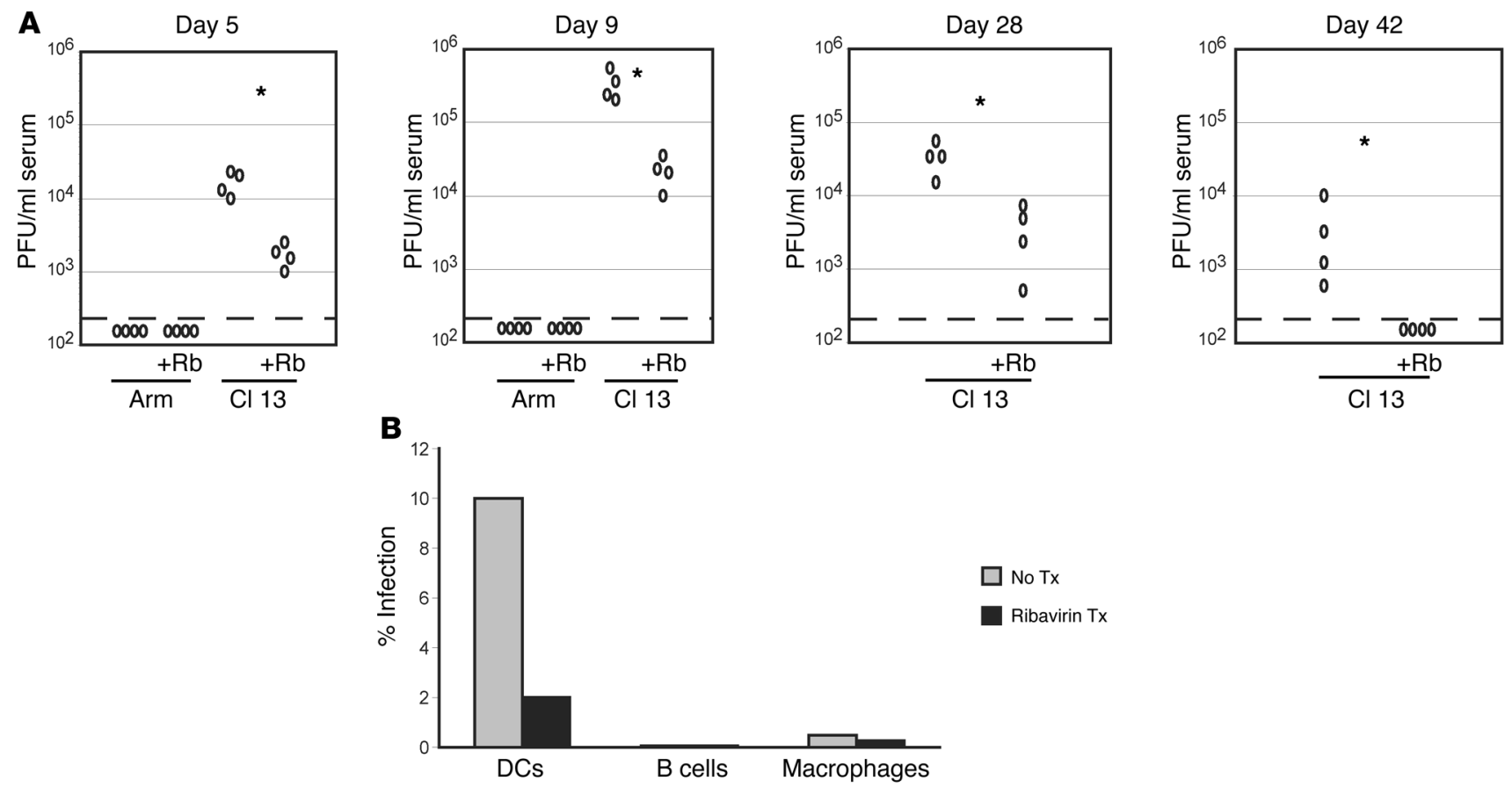

Figure 4

Decreased infection of DCs and long-term control of viral replication following early antiviral therapy. (A) Serum viral titers were determined on the indicated days from LCMV Arm- or Cl 13-infected mice that were either left untreated or treated on days 1-8 with ribavirin (Rb). Data are expressed as plaque-forming units per milliliter of serum. The dashed line indicates the lower limit of detection (250 PFU/ml serum). Each circle represents a single animal. *Statistically significant difference of $P<0.03$. (B) Splenic DCs, B cells, and macrophages were sorted on day 9 from LCMV Cl 13-infected animals that were either left untreated (gray bars) or treated with ribavirin (black bars). The frequency of cells producing infectious virus in each sorted population was determined by an infectious center assay. Data represent 2 experiments containing pools from 4 mice per group. Tx, treatment.

and TNF- $\alpha$-producing cells was observed (Figure 2B), equivalent to the reduced levels observed during $\mathrm{Cl} 13$ infection (Figure 1B). Virus-specific $\mathrm{CD}^{+} \mathrm{T}$ cells primed in Arm-infected animals similarly displayed a 3- and 30-fold decrease, respectively, in IL-2 and TNF- $\alpha$ production following transfer into Cl 13-infected animals (Figure 2C). Of particular interest, SMARTA and P14 cells primed in $\mathrm{Cl}$ 13-infected animals resisted inactivation and remained functional upon transfer into Arm-infected recipients (Figure 2, $\mathrm{B}$ and C). Similar numbers of SMARTA and P14 cells were observed following transfer into Arm- or Cl 13-infected animals (data not shown), indicating that the functional rescue was not due to selection of a small number of cells that resisted inactivation. Thus, the functional capacity of $\mathrm{T}$ cells was determined by the environment into which the cells were placed, rather than where they were primed. These results indicate that priming events during the acute phase of persistent infection were intact and that functional inactivation was not predestined.

We next determined when the instructive signals that potentiated $\mathrm{T}$ cell memory originated and how long-term generation of that memory was affected by the priming events during persistent infection. Earlier we reported the gradual selection of virus-specific $\mathrm{CD}^{+} \mathrm{T}$ cells that resist initial inactivation during persistent infection (2). In fact, during the chronic phase of $\mathrm{Cl} 13$ infection, virus-specific $\mathrm{CD}^{+} \mathrm{T}$ cell responses are approximately $50-80 \%$ of those observed during Arm infection, with a more sustained decrease in TNF- $\alpha$-producing versus IL-2-producing cells. This is in direct opposition to $\mathrm{CD}^{+} \mathrm{T}$ cell responses that remain sup- pressed throughout infection (1). Accordingly, elevated frequencies of cytokine-producing SMARTA cells were present during the chronic phase of $\mathrm{Cl} 13$ infection, and the frequency of cytokineproducing cells was not dictated by the priming environment (Figure 2B). Moreover, regardless of whether SMARTA cells were primed in an Arm- or Cl 13-infected environment, cells transferred into Arm-infected animals had increased levels of IL-7 receptor and Bcl-2 expression compared with cells transferred into $\mathrm{Cl} 13-$ infected animals (Supplemental Figure 1; supplemental material available online with this article; doi:10.1172/JCI26856DS1), consistent with the development of a memory T cell phenotype (39, 40). In contrast to virus-specific $\mathrm{CD}^{+} \mathrm{T}$ cells, cytokine-producing $\mathrm{CD}^{+} \mathrm{T}$ cells were not selected over time in $\mathrm{Cl} 13$-infected mice (Figure 2C), and despite the initial priming environment, transfer into $\mathrm{Cl} 13$-infected mice resulted in long-term depression of $\mathrm{CD}^{+}$ $\mathrm{T}$ cell responses (Figure $2 \mathrm{C}$ ). Most importantly, the prolonged functional impairment of virus-specific $\mathrm{CD}^{+} \mathrm{T}$ cells was prevented by early transfer out of the $\mathrm{Cl} 13$ environment (Figure 2C). These data indicate $\mathrm{T}$ cell memory development need not be instructed during priming.

Restoration of T cell function during persistent infection. The transfer studies indicated that the loss of T cell function was not a preprogrammed event but instead was due to the effects of increased/ prolonged viral replication. To determine whether functionality could be restored to inactivated $\mathrm{T}$ cells, populations of purified $\mathrm{CD}^{+}$or $\mathrm{CD}^{+} \mathrm{T}$ cells were sorted after Arm or $\mathrm{Cl} 13$ infection and cultured ex vivo. Approximately $2-4 \%$ of $\mathrm{CD}^{+}$and $\mathrm{CD}^{+} \mathrm{T}$ cells 
A
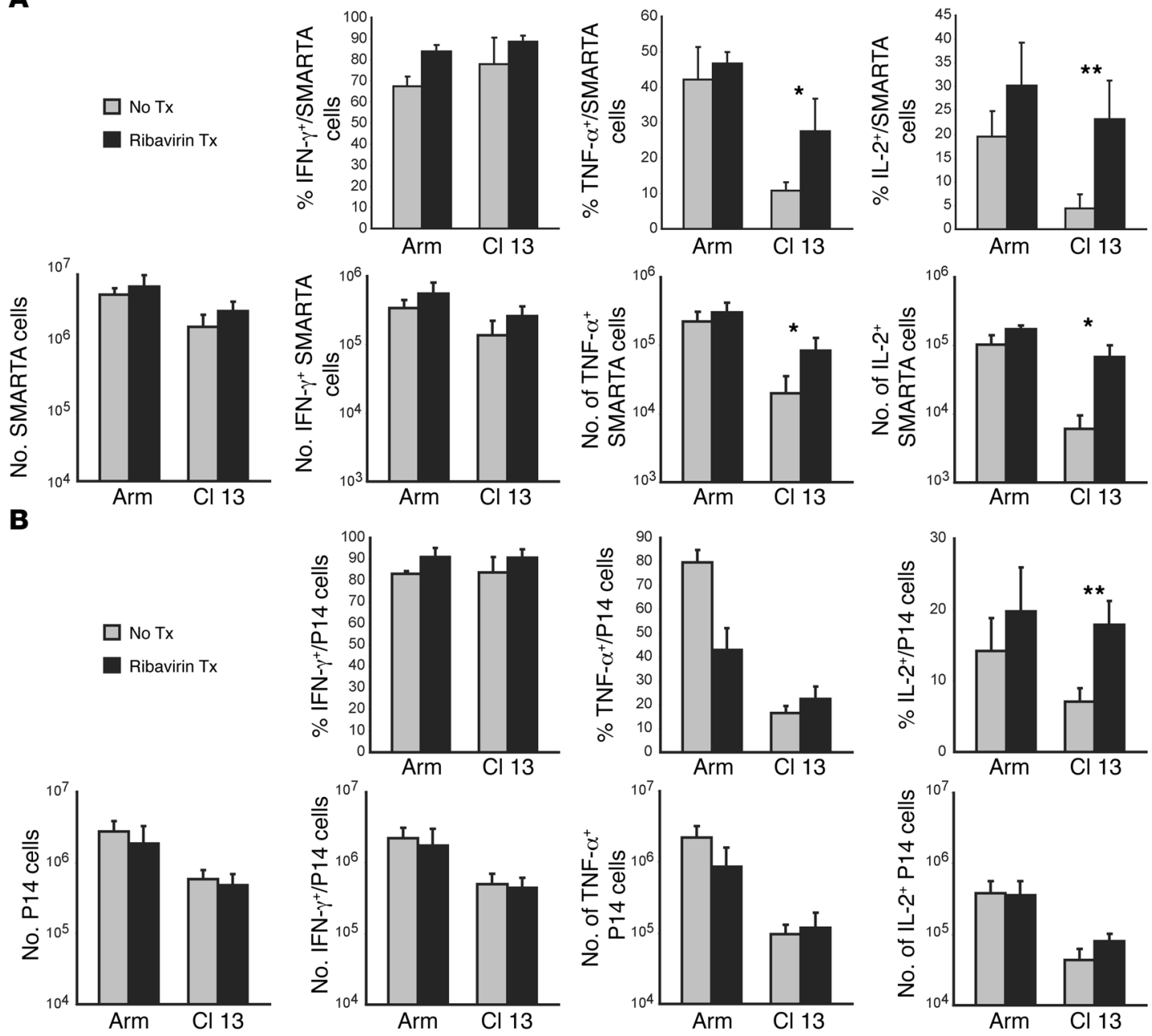

Figure 5

Therapeutically decreasing viral loads prevents CD4+ $\mathrm{T}$ cell inactivation but only minimally preserves CD8 ${ }^{+} \mathrm{T}$ cell function. (A and B) The ability of SMARTA (A) and P14 (B) cells from untreated (gray bars) or ribavirin-treated (black bars) animals to produce IFN- $\gamma$, TNF- $\alpha$, and IL-2 was determined on day 9 after infection with either LCMV Arm (left 2 bars in each graph) or $\mathrm{Cl} 13$ (right 2 bars in each graph). The top graphs of each figure represent the frequency of cytokine-producing SMARTA (A) or P14 (B) cells. The bottom graphs of each figure represent the absolute number of SMARTA (A) or P14 (B) cells and the total number of cytokine-producing SMARTA or P14 cells. The bars represent the average \pm SD of 4 mice in each group in 3 independent experiments. Note that the scales on the $y$ axis differ for the cytokines analyzed. *Statistically significant increase $(P<0.05)$ between the untreated and ribavirin-treated animals; ${ }^{*} P \leq 0.01$.

are infected initially during $\mathrm{Cl} 13$ infection (41), with a small fraction of $\mathrm{CD} 4^{+} \mathrm{T}$ cells (up to $4 \%$ ) becoming persistently infected (42, 43). Furthermore, $\mathrm{CD}^{+} \mathrm{T}$ cells do not express MHC class II molecules (data not shown), thereby excluding the potential for LCMV antigen presentation to the virus-specific cells during the culture period. Ten days after Arm infection, a high frequency of virus-specific $\mathrm{CD}^{+}$and $\mathrm{CD} 8^{+} \mathrm{T}$ cells produced effector molecules, whereas the responsiveness of these cells was severely compromised during $\mathrm{Cl} 13$ infection (Figure 3, A and B). After culture, the percentage of TNF- $\alpha$ - and IL-2-producing SMARTA cells increased 6-fold, constituting nearly $80 \%$ of the optimal response observed during Arm infection (Figure 3A). Similarly, virus-specific $\mathrm{CD}^{+} \mathrm{T}$ cell responses from $\mathrm{Cl} 13$-infected animals recovered completely, i.e., the frequency of IFN- $\gamma$-, TNF- $\alpha$-, and IL-2-producing cells equaled the levels observed during Arm infection (Figure 3B). Reversal was not caused by proliferation of a small number of TNF- $\alpha-$ or IL-2- producing cells, since proliferation did not occur during culture (based on CFSE dilution; data not shown). Moreover, the ratio of SMARTA and P14 cells to endogenous CD4 and CD8 populations, respectively, did not change during the culture period (data not shown), as would be expected if functional virus-specific $\mathrm{T}$ cells had grown selectively.

To determine whether $\mathrm{T}$ cell responsiveness could be restored following extended periods of viral replication, $\mathrm{CD}^{+}$and $\mathrm{CD} 8^{+}$ $\mathrm{T}$ cells were sorted 30 days after $\mathrm{Cl} 13$ or Arm infection. Virusspecific $\mathrm{CD} 4^{+} \mathrm{T}$ cell responses during the chronic phase of $\mathrm{Cl} 13$ infection are approximately $50-80 \%$ of those observed during Arm infection due to a survival advantage of the few cells that initially resist inactivation (2). Consequently, on day 30 after Arm and Cl 13 infection, SMARTA cell responses were only slightly decreased (Figure 3A), and the 4-day culture period only minimally increased the frequency of cells able to produce TNF- $\alpha$ and did not restore 

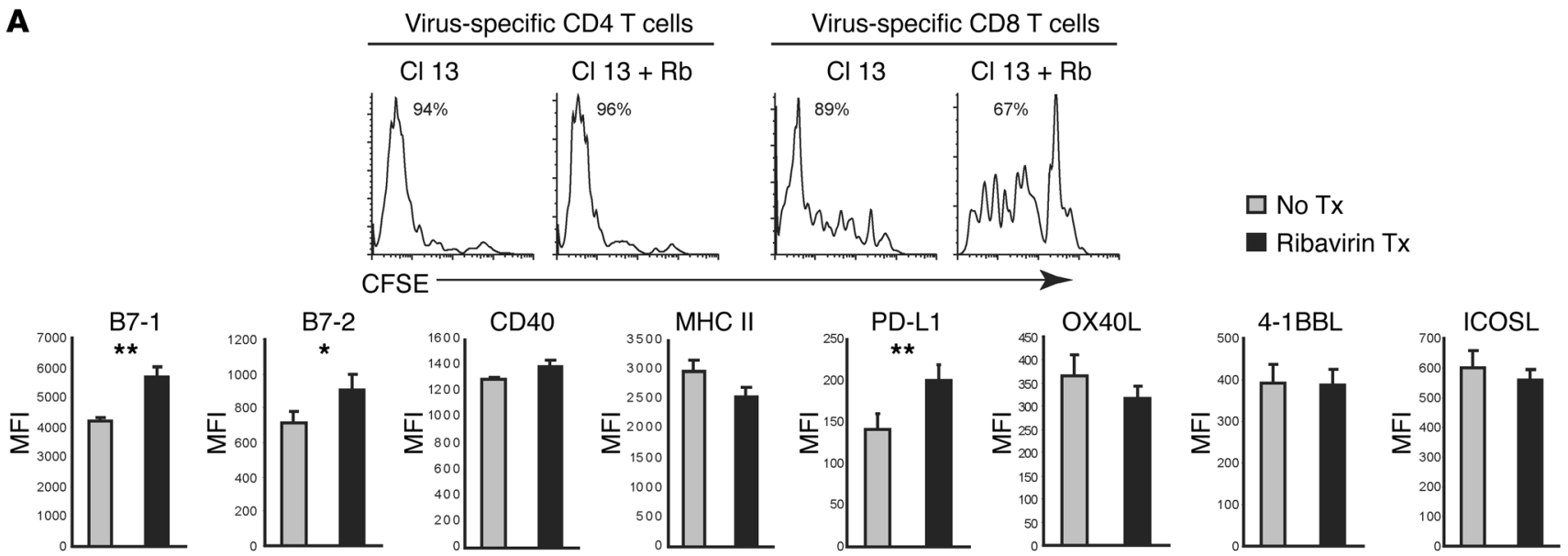

B
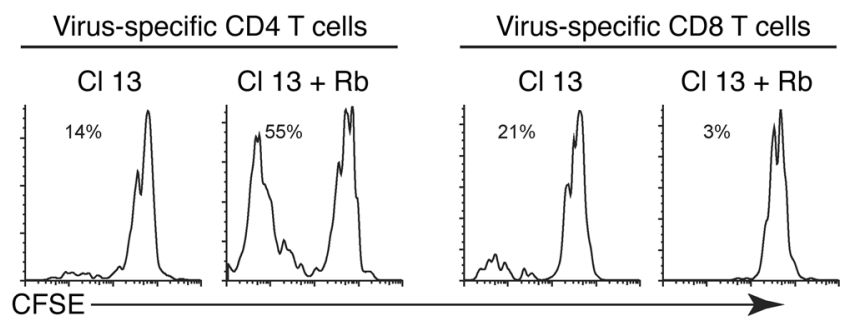

\section{№ Tx \\ - Ribavirin Tx}
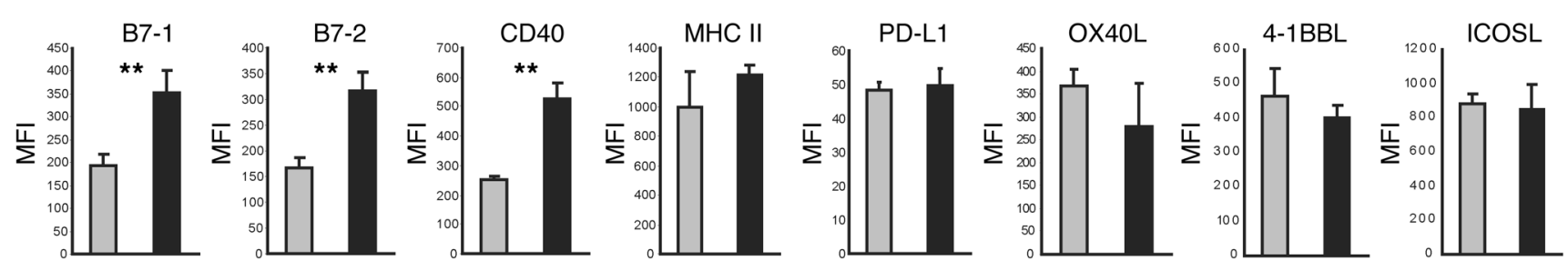

\section{C}
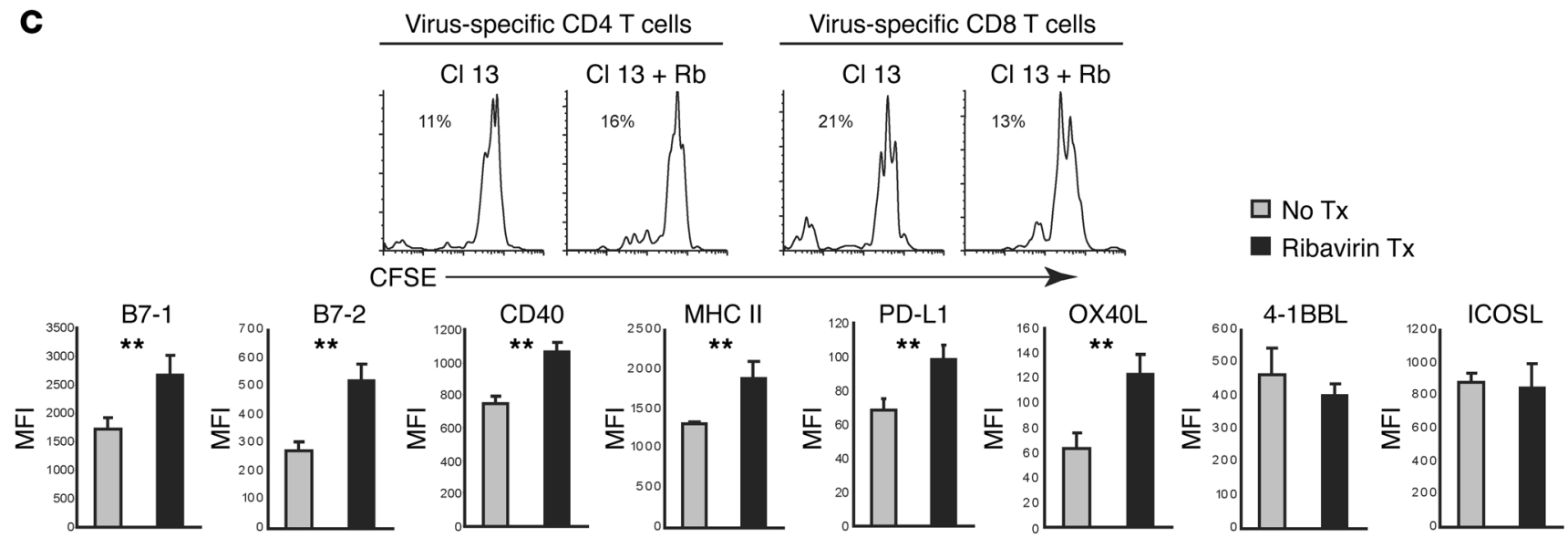

Figure 6

Decreasing viral replication increases CD4+ $\mathrm{T}$ cell stimulation and costimulatory molecule expression by APCs. (A-C) On day 9 after infection, splenocytes were isolated from mice infected with LCMV Cl 13 and either left untreated $(\mathrm{Cl} 13)$ or treated with ribavirin $(\mathrm{Cl} 13+\mathrm{Rb})$. DCs $(\mathbf{A})$, $B$ cells (B), or macrophages (C) were then sorted and cultured separately with CFSE-labeled naive SMARTA, or P14 cells. No exogenous peptide was added to the cultures. Histograms show gating on SMARTA (left histograms) and P14 (right histograms) cells and illustrate CFSE dilution 3 days after culture. The number in each histogram represents the percentage of cells in each culture that divided. The MFI of the indicated costimulatory molecules on DCs (A), B cells (B), and macrophages (C) from untreated (gray bars) and ribavirin-treated (black bars) Cl 13-infected animals was determined on day 9 after infection. These data represent 2 experiments containing 4 mice per group. PD-L1, programmed death ligand; OX40L, OX40 ligand (CD134); 4-1BBL, 41BB ligand (CD137L); ICOSL, inducible costimulatory molecule ligand. ${ }^{*} P<0.05 ;{ }^{* \star} P<0.01$.

IL-2 production (Figure 3A). On the other hand, the percentage of virus-specific $\mathrm{CD}^{+} \mathrm{T}$ cells that produced TNF- $\alpha$ increased 3 -fold following the 4-day culture (yet reached only $60 \%$ of the response observed during the Arm infection), whereas no increase in the 
frequency of IL-2-producing cells was observed (Figure 3B). Again, no proliferation of virus-specific cells was observed in the culture. Thus, we conclude that $\mathrm{CD}^{+}$and $\mathrm{CD}^{+} \mathrm{T}$ cells have the potential to regain responsiveness following inactivation; however, functional recovery wanes over extended periods of viral exposure.

Prevention of T cell inactivation in vivo. Since $T$ cell activity could be resurrected by removal from the persistently infected environment, we determined whether inactivation could be prevented in vivo by therapeutically decreasing viral titers. To address this issue, Armor $\mathrm{Cl} 13$-infected mice were treated with the antiviral drug ribavirin beginning 1 day after infection. Compared to the viral loads during untreated $\mathrm{Cl} 13$ infection, ribavirin treatment decreased viral titers by 1 log through the priming phase of $\mathrm{Cl} 13$ infection (day 5 after infection) and by 1.5 logs when the infection transitioned into a persistent phase (day 9 after infection; Figure 4A). Accompanying these lower viral titers in $\mathrm{Cl} 13$-infected animals treated with ribavirin was a $50-80 \%$ reduction in the percentage of infected DCs (Figure 4B), indicating that the treatment decreased the frequency of infected cells. Other APC populations (B cells and macrophages) showed only a minimal reduction in infection, although less than $0.5 \%$ of these cells were productively infected by Cl 13 (Figure 4B). Because early treatment with ribavirin had such a substantial impact on LCMV-specific T cell responses after $\mathrm{Cl} 13$ infection, we next evaluated whether the immunological benefit was retained into the chronic phase of infection. Early treatment with ribavirin (on days 1-8) during $\mathrm{Cl} 13$ infection had sustained antiviral effects, i.e., a $1 \log$ decrease in serum viral titers was observed in ribavirin-treated versus untreated animals through day 28 after infection despite the discontinuation of treatment, and by day 42 infectious virus was undetectable in the treated animals (Figure 4A), indicating that early alterations in viral replication have a long-term impact on viral control.

Without ribavirin treatment the frequency and number of TNF- $\alpha-$ and IL-2-producing SMARTA and P14 cells decreased significantly during $\mathrm{Cl} 13$ infection (Figure 5, A and B). In comparison, treatment of $\mathrm{Cl} 13$-infected animals with ribavirin stimulated a 3 -fold increase in TNF- $\alpha$ - and 5 -fold increase in IL-2-producing SMARTA cells (Figure 5A). Following ribavirin administration to $\mathrm{Cl} 13$-infected animals, the frequencies of TNF- $\alpha$ - and IL-2-producing SMARTA cells were similar to those observed during Arm infection (not significant, $P>0.1$; Figure $5 \mathrm{~A}$ ), indicating that early reductions in viral infection prevented $\mathrm{CD} 4^{+} \mathrm{T}$ cell inactivation. Similar data were obtained with the endogenous (i.e., hostderived) LCMV-GP ${ }_{61-80} \mathrm{CD}^{+} \mathrm{T}$ cell responses (data not shown). Although ribavirin treatment did not significantly increase the absolute number of SMARTA cells during Arm or Cl 13 infection, it did induce a significant 4-fold and 10-fold increase, respectively, in the absolute number of TNF- $\alpha$ - and IL-2-producing SMARTA cells (Figure 5A), indicating that the functional recovery following ribavirin treatment is not limited to the maintenance of a small number of cells, but rather a circumvention of the normal process of $\mathrm{CD} 4^{+} \mathrm{T}$ cell inactivation.

In contrast to the preserved $\mathrm{CD}^{+} \mathrm{T}$ cell response, decreasing viral titers during $\mathrm{Cl} 13$ infection only partially prevented $\mathrm{CD}^{+} \mathrm{T}$ cell inactivation. Ribavirin treatment of $\mathrm{Cl} 13$-infected animals did not increase the frequency of TNF- $\alpha$-producing P14 cells, which remained similar to that in untreated $\mathrm{Cl} 13$-infected animals (Figure 5B). However, the frequency of IL-2-producing P14 cells rose a significant 2.5-fold following treatment of $\mathrm{Cl} 13$-infected animals, equal to the levels observed during Arm infection (Figure 5B).
Ribavirin treatment of Arm-infected animals had no impact on IFN- $\gamma$ or IL- 2 production by P14 cells, although it did decrease their TNF- $\alpha$ production (Figure 5B), suggesting that decreasing viral titers early during Arm infection may alter the functionality of $\mathrm{CD}^{+} \mathrm{T}$ cell responses. Ribavirin treatment did not significantly impact the absolute number of P14 cells (Figure 5B) or the absolute number of TNF- $\alpha$-producing P14 cells. However, there was a 1.8 -fold increase in the absolute number of IL-2-producing P14 cells $(P=0.06$; Figure $5 \mathrm{~B})$.

Administration of ribavirin during the chronic phase of infection (treatment on days 20-27) had no impact on established antiviral $\mathrm{CD}^{+}$or $\mathrm{CD}^{+} \mathrm{T}$ cell responses (data not shown), in spite of significantly decreasing viral replication 6 -fold $\left(6.1 \times 10^{4} \pm 1.9 \times 10^{3}\right.$ $\mathrm{PFU} / \mathrm{ml}$ serum in untreated mice versus $1 \times 10^{4} \pm 1.9 \times 10^{3} \mathrm{PFU} / \mathrm{ml}$ serum in ribavirin-treated mice; $P<0.001)$. Moreover, there was no apparent change in the level of endogenous $\mathrm{T}$ cell responses at this time, suggesting that the induction of naive $T$ cell responses during periods in which virus levels are therapeutically suppressed does not substantially impact the antiviral $\mathrm{T}$ cell pool. Overall these data indicate that it may be easier to prevent $T$ cell inactivation during the acute phase of a persistent infection than to restore $\mathrm{T}$ cell functions during the chronic phase.

Because high levels of antigen presentation are associated with the loss of T cell function $(15,44)$, we next determined whether the reduction in virus infection following ribavirin treatment decreases T cell stimulation. Three populations of APCs (DCs, B cells, and macrophages) from treated and untreated $\mathrm{Cl} 13$-infected animals were isolated at day 9 after infection and incubated with naive SMARTA or P14 cells. DCs obtained from untreated Cl 13-infected animals induced nearly all the naive P14 cells to proliferate (Figure 6A). Consistent with the decreased levels of DC infection (Figure 4B), DCs from Cl 13-infected animals treated with ribavirin stimulated substantially less $\mathrm{CD}^{+} \mathrm{T}$ cell proliferation (Figure 6A). A decrease in the ability of $\mathrm{B}$ cells and macrophages to stimulate $\mathrm{CD}^{+} \mathrm{T}$ cells was also observed in $\mathrm{Cl} 13$-infected animals treated with ribavirin, although these cells were dramatically less efficient than DCs at stimulating $\mathrm{CD}^{+} \mathrm{T}$ cell proliferation (Figure 6 , $\mathrm{B}$ and $\mathrm{C})$. Interestingly, despite the lower levels of DC infection (Figure 4B), DCs from Cl 13-infected, ribavirin-treated animals induced levels of $\mathrm{CD}^{+} \mathrm{T}$ cell proliferation similar to those induced by DCs from untreated animals (Figure 6A). Although neither B cells nor macrophages served as efficient stimulators of $\mathrm{CD}^{+} \mathrm{T}$ cells during $\mathrm{Cl} 13$ infection (Figure 6, B and C), B cells from Cl 13infected animals treated with ribavirin acquired the capacity to efficiently stimulate $\mathrm{CD}^{+} \mathrm{T}$ cell responses (Figure $6 \mathrm{~B}$ ). To demonstrate that the observed differences in $\mathrm{T}$ cell proliferation resulted from alterations in endogenous presentation/stimulatory capacity by the sorted APCs, not an inherent inability to stimulate T cells, we labeled the APCs with $\mathrm{GP}_{61-80}$ (SMARTA) or $\mathrm{GP}_{33-41}(\mathrm{P} 14)$ peptide. By this means the proliferation of approximately $90 \%$ of the SMARTA and P14 cells was induced (data not shown).

Along with the reduced viral replication after ribavirin treatment, there was a significant increase in the expression of multiple costimulatory molecules on DCs, B cells, and macrophages (Figure 6, A-C). Consistent with the newly acquired ability to stimulate $\mathrm{T}$ cells following ribavirin treatment, the increased costimulatory molecule expression was most notable on B cells, in which there was an approximately 2 -fold increase in the expression of B7-1, B7-2, and CD40 (Figure 6B). Costimulatory molecule expression also increased on macrophages in ribavirin-treated ani- 
mals, although these cells did not efficiently stimulate naive $\mathrm{CD} 4^{+}$ $\mathrm{T}$ cell responses (Figure $6 \mathrm{C}$ ). This increase was not a direct result of the ribavirin per se, since identical treatment of Arm-infected animals did not enhance costimulatory molecule expression (data not shown). Moreover, not all of the costimulatory molecules analyzed were enhanced following ribavirin administration, illustrating the differential regulation/dysregulation of APCs during persistent infection.

\section{Discussion}

Our studies document the highly adaptable nature of $\mathrm{T}$ cell functions and show that $\mathrm{CD}^{+}$and $\mathrm{CD}^{+} \mathrm{T}$ cell effector and memory development are not hardwired processes but, instead, are continually modulated by signals from the environment. The discovery that $\mathrm{T}$ cell responses are alterable led to 4 findings. First, $\mathrm{T}$ cell function that is lost during persistent infection can be restored or preserved by either removing the $\mathrm{T}$ cells from the antigenic environment or administering antiviral therapy in vivo. Second, functional recovery is more difficult to achieve the longer $\mathrm{CD}^{+}$and $\mathrm{CD}^{+} \mathrm{T}$ cells remain in the presence of persistent viral replication. Third, the mechanisms that potentiate $\mathrm{CD} 4^{+}$ $\mathrm{T}$ cell inactivation apparently differ from those that modulate $\mathrm{CD}^{+} \mathrm{T}$ cell function. That is, by decreasing viral titers in vivo, $\mathrm{CD}^{+} \mathrm{T}$ cell inactivation can be prevented, whereas $\mathrm{CD}^{+} \mathrm{T}$ cells still become largely nonresponsive. Fourth, $\mathrm{CD} 4^{+} \mathrm{T}$ cell recovery following early antiviral therapy correlates with an increased ability of APCs to costimulate T cells. Importantly, these collective findings provide what we believe to be the first insight into the mechanisms that induce $T$ cell inactivation during persistent viral infection versus those that may maintain it (45).

Virus-specific $\mathrm{CD}^{+}$and $\mathrm{CD}^{+} \mathrm{T}$ cell responses are initially robust during persistent infection; however, T cells rapidly become nonresponsive in temporal association with the viral transition into persistence. Previous studies have shown that following in vitro priming, functional effector and memory $\mathrm{T}$ cell development is observed (15-21). However, these studies focused on the outcome of a single antigenic encounter and did not address the role of extrinsic factors in $\mathrm{T}$ cell development or how the developmental program is modulated by repetitive stimulation. We show that unlike expansion and contraction, which are programmed during the initial priming interaction (15-19), $\mathrm{CD}^{+}$and $\mathrm{CD}^{+} \mathrm{T}$ cell function is not hardwired but instead can be altered after priming. Functional alterations occur rapidly in response to persisting viral antigens, as virus-specific $T$ cells primed during an acute infection (in a manner that would otherwise yield a functional response) become inactivated 4 days following transfer into an environment with persistent antigen and fail to develop into memory $T$ cells. In contrast, $\mathrm{CD}^{+}$and $\mathrm{CD}^{+} \mathrm{T}$ cells primed in an environment with a heavy antigenic burden can recover from the seemingly inevitable inactivation and ultimately develop into memory $T$ cells by transfer into an environment in which the virus is cleared acutely. The ability to rapidly adjust to the antigenic environment (although apparently detrimental in the case of persistent viral infections) explains how different $\mathrm{T}$ cell functions can be elicited depending on the type and duration of viral infection.

A fundamental problem preventing the eradication of persistent viral infections is the early loss and continued lack of effective $\mathrm{T}$ cell responses. During persistent viral infections of humans such as HIV, HCV, and HBV, the administration of antiviral therapy can decrease viral replication and correspondingly enhance $T$ cell responses $(6,10,22-28)$. However, it is unclear from these studies whether the increased $T$ cell activity was due to the functional restoration of nonresponsive $\mathrm{T}$ cells or to the generation of new effector $T$ cells. To specifically distinguish between these 2 possibilities, we used traceable populations of virus-specific $\mathrm{T}$ cells that were present and primed at the time of infection and could be distinguished from new thymic emigrants. Our studies clearly indicate that virus-specific $T$ cells still retain potential functional capacity despite periods of inactivation and, importantly, T cell activity can be fixed in antigen-experienced, nonresponsive $T$ cells during a persistent viral infection. Although the ability to rescue $\mathrm{T}$ cell responses wanes over extended periods of inactivation, indicating a progressive imprinting on these cells, components of $\mathrm{CD}^{+}$and $\mathrm{CD}^{+} \mathrm{T}$ cell function remain intact and can be restored throughout persistent infection.

Our studies suggest that the early administration of therapies that decrease viral titers by as little as 1 log can have a substantial impact on the quality of the ensuing $\mathrm{T}$ cell responses, particularly $\mathrm{CD}^{+} \mathrm{T}$ cell activity, even in the face of ongoing levels of viral replication. Importantly, the early decrease in viral infection and enhanced $T$ cell activity facilitated long-term control of viral replication well after the therapies were removed. Thus, we demonstrate that there is an optimal time for therapy during persistent viral infection. Administration of therapy late during the chronic stage of infection may not restore function to inactivated $T$ cells, whereas, in contrast, it had a dramatic effect on sustaining function during the acute phase of infection. This finding is consistent with what is observed during HIV infection, where T cell responses are more readily restorable during the acute rather than the chronic phase of infection $(23,26,29,30)$, and suggests that an intrinsic functional defect likely accumulates in nonresponsive $T$ cells with extended periods of inactivation. It is important to note that although therapy did not restore function during the chronic phase of infection, treatment at this time may still be beneficial when given in conjunction with agents that stimulate naive $T$ cell activation, thereby facilitating productive stimulation of these cells. However, therapies to resurrect $\mathrm{T}$ cell activity appear to be most effective when administered early after the establishment of a persistent viral infection.

Excessive antigen stimulation has previously been reported to induce $\mathrm{T}$ cell nonresponsiveness $(15,44)$. However, hyperstimulation appears not to play a major role in our studies, since DCs from ribavirin-treated mice retained an ability to stimulate SMARTA cells similar to that of cells from untreated mice, and $B$ cells actually became competent stimulators of naive $\mathrm{CD} 4^{+} \mathrm{T}$ cells following ribavirin treatment. A contributing cause of $\mathrm{CD} 4^{+}$ $T$ cell inactivation may be "incorrect" or insufficient stimulation by APCs during the effector phase of a $\mathrm{Cl} 13$ virus infection. This is supported by our data showing that ribavirin-treated mice had elevated levels of costimulatory molecules on MHC class II-bearing cells. Since the signs of CD $4^{+} \mathrm{T}$ cell inactivation are not overtly manifest at day 5 after $\mathrm{Cl} 13$ infection, our data further suggest that $\mathrm{CD}^{+} \mathrm{T}$ cells may still require costimulation during the effector phase to sustain their function. This is consistent with previous findings showing that prevention of costimulation during the chronic phase of $\mathrm{Cl} 13$ infection diminishes antiviral $\mathrm{CD}^{+} \mathrm{T}$ cell responses and prevents control of viral replication (46). Thus, costimulation by APCs may be required at all phases of infection to sustain productive $\mathrm{CD} 4^{+} \mathrm{T}$ cell responses and prevent inactivation. However, $\mathrm{CD}^{+} \mathrm{T}$ cell function is not fully restored by an 
early decrease in viral titers, indicating that different/additional signals, distinct from those of $\mathrm{CD}^{+}{ }^{+} \mathrm{T}$ cells, likely modulate $\mathrm{CD} 8^{+}$ $\mathrm{T}$ cell inactivation. We are currently determining the precise molecules that sustain $\mathrm{T}$ cell responses and the cell population(s) that display them in order to facilitate the development of therapeutics to prevent inactivation and restore antiviral responses to overcome persistent viral infections.

\section{Methods}

Mice. C57BL/6 $\left(\mathrm{H}-2^{\mathrm{b}}\right.$, Thy $\left.1.2^{+}\right)$mice were from the Rodent Breeding Colony at The Scripps Research Institute. CD4/- mice were bred from homozygous breeding pairs obtained from Jackson Laboratory. The LCMV-GP $61-80^{-}$-specific CD4 ${ }^{+}$TCR transgenic (SMARTA) mice and LCMV$\mathrm{GP}_{33-41-\text { specific CD8 }}{ }^{+}$TCR transgenic (P14) mice have been described previously (47) and were gifts from Hans Hengartner and Rolf Zinkernagel (University Hospital of Zurich, Zurich, Switzerland). All mice were housed under specific pathogen-free conditions. Mouse experiments conformed to the requirements of the NIH and were approved by The Scripps Research Institute Animal Research Committee.

Virus. In all experiments, 6- to 8-week-old C57BL/6 mice were infected i.v. with $2 \times 10^{6} \mathrm{PFU}$ of LCMV Arm Cl $53 \mathrm{~b}$ or LCMV Cl 13 to generate acute or persistent infection, respectively. Stocks were prepared by a single passage on BHK-21 cells. Viral titers were determined by plaque formation on Vero cells. The frequency of productively infected splenic DCs $\left(\mathrm{CD}_{4}{ }^{+}, \mathrm{CD}^{-}, \mathrm{NK} 1.1^{-}, \mathrm{CD} 11 \mathrm{c}^{+}\right)$, B cells $\left(\mathrm{CD} 45^{+}, \mathrm{CD} 3^{-}, \mathrm{NK} 1.1^{-}, \mathrm{CD} 11 \mathrm{c}^{-}\right.$, $\left.\mathrm{CD} 19^{+}\right)$, and macrophages $\left(\mathrm{CD}^{+} 5^{+}, \mathrm{CD} 3^{-}, \mathrm{NK} 11^{-}, \mathrm{CD} 11 \mathrm{c}^{-}, \mathrm{CD} 11 \mathrm{~b}^{+}\right)$was determined by sorting the individual population and performing limiting dilution plaque assays (infectious center assays) on Vero cells (48). The cells were sorted using the FACSVantage (BD). Post-sort purities for each population were at least $99 \%$.

T cell isolation and adoptive transfers. $\mathrm{CD}^{+}$and $\mathrm{CD} 8^{+} \mathrm{T}$ cells were purified from the spleens of naive SMARTA and P14 mice, respectively, by negative selection (StemCell Technologies), and $10^{3}$ purified cells from each population were cotransferred into C57BL/ 6 mice i.v. The mice were infected 2 days later with $2 \times 10^{6} \mathrm{PFU}$ LCMV, i.v. For the transfer experiments to determine the plasticity of functional programming, spleens from Arm- or Cl 13-infected mice that had received SMARTA and P14 cells were harvested. Next, B cells were depleted (>99\% removed; data not shown) from the splenocytes by positive selection with CD19 MACS beads (Miltenyi Biotec), and the remaining B cell-depleted, untouched (non-antibodybound) splenocytes were transferred into mice that had been infected in parallel 5 days earlier with Arm or $\mathrm{Cl} 13$ but that had not initially received SMARTA or P14 cells. The absolute number of SMARTA and P14 cells in the spleen was determined by multiplying the frequency of Thy $1.1^{+}$cells (determined flow cytometrically) by the total number of splenocytes.

Intracellular cytokine analysis. Total splenocytes were stimulated for 5 hours with $5 \mu \mathrm{g} / \mathrm{ml}$ of the MHC class II-restricted LCMV-GP $61-80$ peptide or $2 \mu \mathrm{g} / \mathrm{ml}$ of the MHC class I-restricted LCMV-GP $33-41$ peptide (both >99\% pure; Synpep Corp.) in the presence of $50 \mathrm{U} / \mathrm{ml}$ recombinant murine IL-2 (R\&D Systems) and $1 \mathrm{mg} / \mathrm{ml}$ brefeldin A (Sigma-Aldrich). The addition of IL-2 to the ex vivo stimulation did not alter cytokine production (data not shown). Flow cytometric analysis was performed using the Digital LSR II (BD). Forward- versus side-scatter profiles were used to define the live population, and gates were set based on antibody isotype controls and cells that stained negative for the protein of interest.

T cell culture assays. To determine the restorability of $\mathrm{T}$ cell function, total $\mathrm{CD}^{+}$or $\mathrm{CD}^{+} \mathrm{T}$ cells were sorted flow cytometrically ( $>99 \%$ purity) from pooled splenocytes of 2-3 animals that had received SMARTA and P14 cells and been infected 10,30, or 50 days earlier with either LCMV Arm or $\mathrm{Cl} 13$. The sorted $\mathrm{T}$ cell populations were individually cultured for 4 days with $200 \mathrm{U} / \mathrm{ml}$ recombinant murine IL-2 (R\&D Systems). The cells were cultured in complete medium (RPMI 1640 supplemented with $10 \%$ fetal bovine serum, $1 \% \mathrm{Na}$ pyruvate, $10 \mathrm{mM}$ HEPES, $1 \%$ nonessential amino acids, and $500 \mathrm{U} / \mathrm{ml}$ penicillin and streptomycin). To obtain APCs for the post-culture peptide stimulations, splenocytes from an Arm-infected animal (3 days after infection) were depleted of T cells using Thy1.2 MACS beads (Miltenyi Biotec). APCs were isolated 3 days after infection to allow proper maturation in an inflammatory environment. After the 4-day culture period, the T cells were incubated with the T cell-depleted APCs and $\mathrm{GP}_{61-80}$ or $\mathrm{GP}_{33-41}$ peptide (for the $\mathrm{CD}^{+}$or $\mathrm{CD}^{+} \mathrm{T}$ cell stimulations, respectively) for 5 hours, followed by intracellular cytokine analysis.

To evaluate the stimulatory capacity of different splenic APC populations, splenic DCs $\left(\mathrm{CD}^{2} 5^{+}, \mathrm{CD} 3^{-}, \mathrm{NK} 1.1^{-}, \mathrm{CD} 11 \mathrm{c}^{+}\right)$, B cells $\left(\mathrm{CD}^{+} 5^{+}, \mathrm{CD} 3^{-}\right.$, NK1.1 $\left.1^{-}, \mathrm{CD} 11 \mathrm{c}^{-}, \mathrm{CD} 19^{+}\right)$, and macrophages (CD45+ ${ }^{+}, \mathrm{CD} 3^{-}, \mathrm{NK}^{-1} 1^{-}, \mathrm{CD} 11 \mathrm{c}^{-}$, $\mathrm{CD}_{11} \mathrm{~b}^{+}$) were sorted using the FACSVantage (BD). Post-sort purities for each population were at least $99 \%$. The sorted APC populations were then individually mixed with CFSE-labeled naive SMARTA or P14 cells at a 2:1 ratio. The cells were cultured in complete medium supplemented with $50 \mu \mathrm{M}$ $\beta$-mercaptoethanol for 3 days. Where indicated, the $\mathrm{GP}_{61-80}$ or $\mathrm{GP}_{33-41}$ peptide was added to the cultures.

Ribavirin treatment. $10^{3}$ each of SMARTA and P14 cells were cotransferred into C57BL/ 6 mice that were infected 2 days later with LCMV. Mice were treated with $100 \mathrm{mg} / \mathrm{kg}$ ribavirin (1- $\beta$-D-ribofuranosyl-1,2,4triazole-3-carboxamide; Virazole, ICN Pharmaceuticals Inc.) in PBS. This dose of ribavirin maximizes the efficacy of the drug against LCMV replication, while avoiding toxicity to the host (49). In agreement with our current studies, mice treated with this dose of ribavirin failed to show toxicity. The treatment was administered once daily intraperitoneally on days 1-8 or 20-27 after LCMV infection. Control mice were injected in parallel with PBS. Ribavirin has previously been shown to lower viral titers in animals persistently infected with LCMV (50) by specifically interfering with viral replication (51).

In vivo cytotoxicity assays. Splenocytes from naive syngeneic mice were either left unlabeled or were labeled with $5 \mu \mathrm{g} / \mathrm{ml}$ of the MHC class I-restricted peptides $\mathrm{GP}_{33-41}$ or $\mathrm{NP}_{396-404}$. These target cell populations were then differentially labeled with CFSE $(2.5 \mu \mathrm{g} / \mathrm{ml}, 1 \mu \mathrm{g} / \mathrm{ml}$, or $0.2 \mu \mathrm{g} / \mathrm{ml})$ and transferred i.v. $\left(5 \times 10^{6}\right.$ cells of each population) into mice previously infected with LCMV. Fifteen hours after transfer, splenocytes were isolated from the recipient mice and analyzed for CFSE expression by flow cytometry. Percent lysis was calculated as [1- $(r$ naive $/ r$ sample $) \times 100]$, in which $r$ represents the ratio of the peptide-unlabeled peak versus the peptide-labeled peak for each sample.

Statistics. One-tailed Student's $t$ tests were performed using SigmaStat 2.0 software (Systat Software Inc.) to determine statistical significance $(P \leq 0.05)$.

\section{Acknowledgments}

This is publication number 17509-NP from the Viral Immunobiology Laboratory, Department of Molecular and Integrative Neuroscience, The Scripps Research Institute. We thank Dae Young, P. Truong, A. Tishon, and H. Lewicki for technical assistance. This work was supported by NIH grants AI09484 (to M.B.A. Oldstone) and NS048866-01 (to D.B. McGavern), a Dana Foundation grant (to D.B. McGavern), and NIH training grant AI07244-22 (to D.G. Brooks).

Received for publication September 17, 2005, and accepted in revised form April 4, 2006.

Address correspondence to: David G. Brooks, 10550 North Torrey Pines Road, La Jolla, California 92037, USA. Phone: (858) 784-9461; Fax: (858) 784-9981; E-mail: dbrooks@scripps.edu. 
1. Wherry, E.J., Blattman, J.N., Murali-Krishna, K., van der Most, R., and Ahmed, R. 2003. Viral persistence alters CD8 T-cell immunodominance and tissue distribution and results in distinct stages of functional impairment. J. Virol. 77:4911-4927.

2. Brooks, D.G., Teyton, L., Oldstone, M.B., and McGavern, D.B. 2005. Intrinsic functional dysregulation of CD4 $\mathrm{T}$ cells occurs rapidly following persistent viral infection. J. Virol. 79:10514-10527.

3. Ciurea, A., Hunziker, L., Klenerman, P., Hengartner, H., and Zinkernagel, R.M. 2001. Impairment of CD4(+) $\mathrm{T}$ cell responses during chronic virus infection prevents neutralizing antibody responses against virus escape mutants. J. Exp. Med. 193:297-305.

4. Zajac, A.J., et al. 1998. Viral immune evasion due to persistence of activated $\mathrm{T}$ cells without effector function. J. Exp. Med. 188:2205-2213.

5. Lichterfeld, M., et al. 2004. Loss of HIV-1-specific CD8+ T cell proliferation after acute HIV-1 infection and restoration by vaccine-induced HIV-1-specific CD4+ T cells. J. Exp. Med. 200:701-712.

6. Rosenberg, E.S., et al. 1997. Vigorous HIV-1-specific CD4+ $\mathrm{T}$ cell responses associated with control of viremia. Science. 278:1447-1450.

7. Thimme, R., et al. 2001. Determinants of viral clearance and persistence during acute hepatitis $C$ virus infection. J. Exp. Med. 194:1395-1406.

8. Reignat, S., et al. 2002. Escaping high viral load exhaustion: CD8 cells with altered tetramer binding in chronic hepatitis B virus infection. J. Exp. Med. 195:1089-1101.

9. Lechner, F., et al. 2000. CD8+ T lymphocyte responses are induced during acute hepatitis $\mathrm{C}$ virus infection but are not sustained. Eur. J. Immunol. 30:2479-2487.

10. Boni, C., et al. 1998. Lamivudine treatment can restore $\mathrm{T}$ cell responsiveness in chronic hepatitis $\mathrm{B}$. J. Clin. Invest. 102:968-975.

11. Cox, A.L., et al. 2005. Comprehensive analyses of $\mathrm{CD} 8+\mathrm{T}$ cell responses during longitudinal study of acute human hepatitis C. Hepatology. 42:104-112.

12. Volkert, M. 1962. Studies on immunological tolerance to LCM virus. A preliminary report on adoptive immunization of virus carrier mice. Acta Pathol. Microbiol. Scand. 56:305-310.

13. Lechner, F., et al. 2000. Analysis of successful immune responses in persons infected with hepatitis C virus. J. Exp. Med. 191:1499-1512.

14. McMichael, A. 2006. HIV vaccines. Annu. Rev. Immunol. 24:227-255.

15. Iezzi, G., Karjalainen, K., and Lanzavecchia, A. 1998. The duration of antigenic stimulation determines the fate of naive and effector $\mathrm{T}$ cells. Immunity. 8:89-95.

16. Iezzi, G., Scotet, E., Scheidegger, D., and Lanzavecchia, A. 1999. The interplay between the duration of TCR and cytokine signaling determines T cell polarization. Eur. J. Immunol. 29:4092-4101.

17. Van Stipdonk, M.J., Lemmens, E.E., and Schoenberger, S.P. 2001. Naive CTLs require a single brief period of antigenic stimulation for clonal expansion and differentiation. Nat. Immunol. 2:423-429.

18. Kaech, S.M., and Ahmed, R. 2001. Memory CD8+ T cell differentiation: initial antigen encounter triggers a developmental program in naive cells. Nat. Immunol. 2:415-422.

19. Kaech, S.M., Hemby, S., Kersh, E., and Ahmed, R.
2002. Molecular and functional profiling of memory CD8 T cell differentiation. Cell. 111:837-851.

20. Mercado, R., et al. 2000. Early programming of T cell populations responding to bacterial infection. J. Immunol. 165:6833-6839.

21. Williams, M.A., and Bevan, M.J. 2004. Shortening the infectious period does not alter expansion of CD8 T cells but diminishes their capacity to differentiate into memory cells. J. Immunol. 173:6694-6702.

22. Autran, B., et al. 1997. Positive effects of combined antiretroviral therapy on CD4+ T cell homeostasis and function in advanced HIV disease. Science. 277:112-116

23. Altfeld, M., et al. 2001. Cellular immune responses and viral diversity in individuals treated during acute and early HIV-1 infection. J. Exp. Med. 193:169-180.

24. Kamal, S.M., et al. 2004. Pegylated interferon alpha therapy in acute hepatitis C: relation to hepatitis $\mathrm{C}$ virus-specific $\mathrm{T}$ cell response kinetics. Hepatology. 39:1721-1731.

25. Oxenius, A., et al. 2000. Early highly active antiretroviral therapy for acute HIV-1 infection preserves immune function of CD8+ and CD4+ T lymphocytes. Proc. Natl. Acad. Sci. U. S. A. 97:3382-3387.

26. Rosenberg, E.S., et al. 2000. Immune control of HIV-1 after early treatment of acute infection. Nature. 407:523-526.

27. Lauer, G.M., et al. 2005. Full-breadth analysis of $\mathrm{CD} 8+\mathrm{T}$-cell responses in acute hepatitis $\mathrm{C}$ virus infection and early therapy. J. Virol. 79:12979-12988.

28. Barnes, E., et al. 2002. The dynamics of T-lymphocyte responses during combination therapy for chronic hepatitis $\mathrm{C}$ virus infection. Hepatology. 36:743-754.

29. Garcia, F., et al. 2001. The virological and immunological consequences of structured treatment interruptions in chronic HIV-1 infection. AIDS. 15:F29-F40.

30. Ortiz, G.M., et al. 2001. Structured antiretroviral treatment interruptions in chronically HIV1 -infected subjects. Proc. Natl. Acad. Sci. U. S. A. 98:13288-13293.

31. Papasavvas, E., et al. 2000. Enhancement of human immunodeficiency virus type 1 -specific CD4 and CD8 $\mathrm{T}$ cell responses in chronically infected persons after temporary treatment interruption. J. Infect. Dis. 182:766-775.

32. Xiong, Y., et al. 2001. Simian immunodeficiency virus (SIV) infection of a rhesus macaque induces SIV-specific CD8 $(+) \mathrm{T}$ cells with a defect in effector function that is reversible on extended interleukin-2 incubation. J. Virol. 75:3028-3033.

33. Marzo, A.L., et al. 2005. Initial T cell frequency dictates memory CD8+ T cell lineage commitment. Nat. Immunol. 6:793-799.

34. Ahmed, R., Salmi, A., Butler, L.D., Chiller, J.M., and Oldstone, M.B. 1984. Selection of genetic variants of lymphocytic choriomeningitis virus in spleens of persistently infected mice. Role in suppression of cytotoxic $T$ lymphocyte response and viral persistence. J. Exp. Med. 160:521-540.

35. Salvato, M., Borrow, P., Shimomaye, E., and Oldstone, M.B. 1991. Molecular basis of viral persistence: a single amino acid change in the glycoprotein of lymphocytic choriomeningitis virus is associated with suppression of the antiviral cytotoxic T-lymphocyte response and establishment of persistence. J. Virol. 65:1863-1869.

36. Borrow, P., Evans, C.F., and Oldstone, M.B. 1995. Virus-induced immunosuppression: immune system-mediated destruction of virus-infected dendritic cells results in generalized immune suppression. J. Virol. 69:1059-1070.

37. Sevilla, N., et al. 2000. Immunosuppression and resultant viral persistence by specific viral targeting of dendritic cells. J. Exp. Med. 192:1249-1260.

38. Fuller, M.J., Khanolkar, A., Tebo, A.E., and Zajac, A.J. 2004. Maintenance, loss, and resurgence of $T$ cell responses during acute, protracted, and chronic viral infections. J. Immunol. 172:4204-4214.

39. Homann, D., Teyton, L., and Oldstone, M.B. 2001. Differential regulation of antiviral T-cell immunity results in stable CD8+ but declining CD4+ T-cell memory. Nat. Med. 7:913-919.

40. Kaech, S.M., et al. 2003. Selective expression of the interleukin 7 receptor identifies effector CD8 T cells that give rise to long-lived memory cells. Nat. Immunol. 4:1191-1198.

41. Borrow, P., Tishon, A., and Oldstone, M.B. 1991. Infection of lymphocytes by a virus that aborts cytotoxic $\mathrm{T}$ lymphocyte activity and establishes persistent infection. J. Exp. Med. 174:203-212.

42. Ahmed, R., King, C.C., and Oldstone, M.B. 1987. Virus-lymphocyte interaction: $\mathrm{T}$ cells of the helper subset are infected with lymphocytic choriomeningitis virus during persistent infection in vivo. J. Virol. 61:1571-1576.

43. Tishon, A., Southern, P.J., and Oldstone, M.B. 1988. Virus-lymphocyte interactions. II. Expression of viral sequences during the course of persistent lymphocytic choriomeningitis virus infection and their localization to the L3T4 lymphocyte subset. J. Immunol. 140:1280-1284.

44. Singh, N.J., and Schwartz, R.H. 2003. The strength of persistent antigenic stimulation modulates adaptive tolerance in peripheral CD4+ T cells. J. Exp. Med. 198:1107-1117.

45. Barber, D.L., et al. 2005. Restoring function in exhausted CD8 T cells during chronic viral infection. Nature. 439:682-687.

46. Williams, M.A., et al. 2002. Cutting edge: persistent viral infection prevents tolerance induction and escapes immune control following CD28/CD40 blockade-based regimen. J. Immunol. 169:5387-5391.

47. Oxenius, A., Bachmann, M.F., Zinkernagel, R.M., and Hengartner, H. 1998. Virus-specific MHCclass II-restricted TCR-transgenic mice: effects on humoral and cellular immune responses after viral infection. Eur. J. Immunol. 28:390-400.

48. Oldstone, M.B., Salvato, M., Tishon, A., and Lewicki, H. 1988. Virus-lymphocyte interactions. III. Biologic parameters of a virus variant that fails to generate CTL and establishes persistent infection in immunocompetent hosts. Virology. 164:507-516

49. Von Herrath, M.G., et al. 2000. Vaccination to treat persistent viral infection. Virology. 268:411-419.

50. Berger, D.P., Homann, D., and Oldstone, M.B. 2000. Defining parameters for successful immunocytotherapy of persistent viral infection. Virology. 266:257-263.

51. Gessner, A., and Lother, H. 1989. Homologous interference of lymphocytic choriomeningitis virus involves a ribavirin-susceptible block in virus replication. J. Virol. 63:1827-1832. 